Theme: B. Remote Sensing

Subtheme: B2. Remote sensing for water resource management

\title{
Performances of GPM satellite precipitation over the two major Mediterranean islands
}

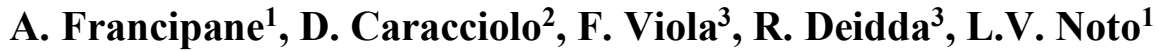 \\ ${ }^{1}$ Dipartimento di Ingegneria Civile, Ambientale, Aereospaziale, e dei Materiali (DICAM), \\ Università di Palermo, viale delle Scienze, 90142 Palermo, Italy \\ ${ }^{2}$ Regional Environmental Protection Agency, Sardinia, via Ciusa 6, 09121 Cagliari, Italy \\ ${ }^{3}$ Dipartimento di Ingegneria Civile, Ambientale e Architettura (DICAAR), \\ Università di Cagliari, via Marengo 2, 09123 Cagliari, Italy
}

\section{Corresponding author: antonio.francipane@unipa.it}

\begin{abstract}
Obtaining accurate high-resolution precipitation fields is still a challenging task. Nowadays, continuous technological evolution of satellite-rainfall estimate systems, which are able to produce low-cost data with a global coverage, are giving significant improvements in precipitation monitoring. The Global Precipitation Measurement (GPM) is the most recent satellite mission and a promising source of rainfall estimates at high spatial and temporal resolutions.

The aim of this study is to assess the reliability of Integrated Multi-satellitE Retrievals for GPM (IMERG) products for the Sardinia and Sicily (Italy). Given the complex morphology and the different precipitation types, originated by stratiform and convective systems as well as by the interaction of steep orography in the coasts with winds carrying on humid air masses from the Mediterranean Sea, both the islands are interesting test sites for the GPM products in the European mid-latitude area.

We selected the GPM post real-time "Final" run product at $0.1^{\circ}$ spatial resolution and half-hour temporal resolution for the period 2015-2016. Evaluation and comparison of the selected product, at the hourly and daily time-scales, are performed by evaluating their consistence with measured data provided by the rain gauge networks of the two islands through statistical and graphical tools.
\end{abstract}

Keywords: GPM, IMERG, Mediterranean islands, rainfall, satellite

\section{Introduction}

Precipitation measurements are fundamental for weather prediction, water resource management, and disaster monitoring [1]. Currently, among the available methods to operatively measure precipitation (i.e., rain gauges, weather radars, and satellite-based sensors), the only practical way to achieve comprehensive estimation of precipitation on a global and regional basis relies on earth observation satellites [2,3]. The most recent satellite mission is the Global Precipitation Measurement (GPM) [4,5,6,7], which is an international constellation of satellites including the Core Observatory satellite and approximately ten partner satellites with the main purpose of establishing the structure and magnitude of variations in precipitation in order to better understand the water and energy cycle [1]. The GPM Core Observatory was launched on February 28, 2014 by a joint effort of NASA and the Japan Aerospace Exploration Agency (JAXA).

Since then, several studies have examined whether the rainfall products from the GPM mission are capable to accurately estimate global precipitation [8,9,10,11,12] and provide the order of magnitude of discrepancies between observations and satellite products highlighting the reasons for such problems $[13,14,15]$. 
In this context, the aim of this study is to test the Integrated Multi-satellitE Retrievals for GPM (IMERG) products against data provided by dense rain gauges over the two major islands of Mediterranean Sea, i.e. Sardinia and Sicily. Because of their complex morphology and variegate precipitation regimes, the two islands are an interesting test site for IMERG products in the European mid-latitude area and, more in general, for complex domains.

\section{Material and Methods}

\subsection{Study area}

With an extension of about $25,700 \mathrm{~km}^{2}$, Sicily is the biggest island of Mediterranean Sea. It is located between the $36^{\circ}$ and $39^{\circ}$ latitudes. Sardinia, which is the second largest island, has an area of about $24,000 \mathrm{~km}^{2}$ and it is located between the $38.8^{\circ}$ and $41.4^{\circ}$ latitudes (Figure 1). The waterfront length of the two islands is similar (1,639 km for Sicily and 1,849 km for Sardinia).
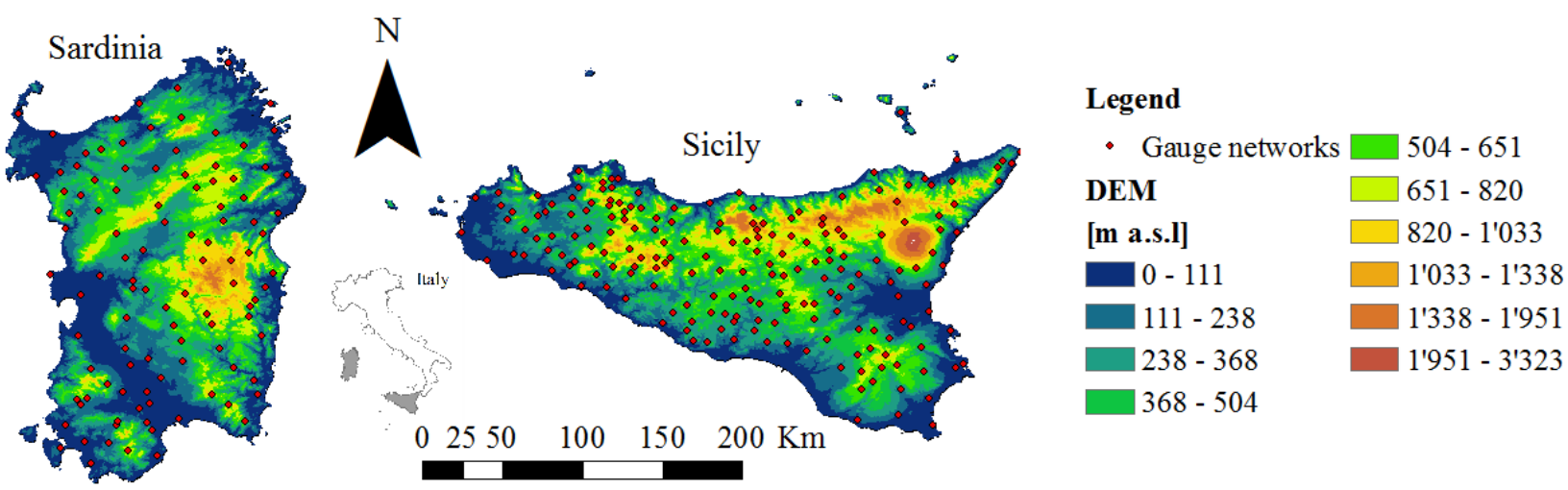

Figure 1 - Digital elevation model (DEM) of the study areas and rain gauges locations (red dots).

The morphology of Sicily is characterized by mountain ranges along the longitudinal direction on the northern side and the Etna volcano on the eastern side (Figure 1). The mean annual precipitation over the island is about $715 \mathrm{~mm}$ with the largest rainfall amount falling during the winter months. Precipitation ranges between $400 \mathrm{~mm}$ (in the southeast) and 1,300 $\mathrm{mm}$ (in the northeast) [16,17]. Almost all of the Sardinian area is flat, except for a long mountain range, called Sardinian-Corse Mountain System, which is located in the eastern part of island, running from north to south, and a smaller isolated mountain range located in the southwest (Figure 1). The climate is Mediterranean as well with rainfall mainly concentrated during autumn and winter. The mean annual precipitation ranges between $500 \mathrm{~mm}$ in lower elevation areas and 1,160 $\mathrm{mm}$ at the highest mountains $[18,19]$.

\subsubsection{Reference rain gauges networks and GPM satellite data}

The rain gauge dataset of Sicily is provided by the Osservatorio delle Acque-Agenzia Regionale per $i$ Rifiuti e le Acque (OA-ARRA) (http://www.osservatorioacque.it/). The dataset includes 195 tipping-bucket rain gauges with a rather uniform spatial distribution, as shown in Figure 1, and an average density equal to about $130 \mathrm{~km}^{2} /$ gauge. Data are retrieved with the hourly resolution.

The rain gauge data set of Sardinia is provided by the Protezione Civile of Cagliari and is made of 105 tipping-bucket rain gauges, with an average density equal to about $228 \mathrm{~km}^{2} /$ gauge (Figure 1). Data are retrieved with high-temporal resolution ( 1 minute).

For both islands, we collected data for the two-year period 2015-2016. Aggregated data at hourly and daily time-scales and spatially interpolated and resampled at the GPM grid resolution were used as reference to evaluate the performance of the GPM satellite data.

GPM dataset comes from the latest version V4 of the IMERG "Final" product, released in spring 2017 (ftp://arthurhou.pps.eosdis.nasa.gov/gpmallversions/V04/) [7,20]. IMERG provides timely 
observation of precipitation at $0.1^{\circ}$ resolution every 30 minutes. IMERG data have been aggregated at the hourly time-scale for both the islands.

\subsubsection{Evaluation indexes}

In order to obtain general information about the performances of IMERG data over the islands, features of rainfall spatial distribution have been investigated using statistical tools. In particular, we used categorical (i.e., Probability of Detection (POD), False Alarm Ratio (FAR), Miss Index (MISS), and Critical Success Index $(C S I)$ ) and volumetric (i.e., Volumetric Hit Index (VHI), Volumetric False Alarm Ratio (VFAR), Volumetric Miss Index (VMI), and Volumetric Critical Success Index $(V C S I))$ indexes, which take into account precipitation and volumetric occurrences, respectively. The volumetric indexes provide additional information beyond the categorical metrics. We used a slightly modified version of such indexes, which take into account a threshold, $t$, above which the precipitation and volumetric occurrences are considered for indexes computation. A $t=0$ indicates evaluation of the entire distribution of simulated versus observed variables. A higher threshold can be used to evaluate the performances in reproducing the occurrences of the higher precipitation quantiles. In this study, the threshold value for categorical indexes was set to the $5^{\text {th }}$, $50^{\text {th }}$ and $95^{\text {th }}$ percentiles at each pixel. For the sake of simplicity, we will use the notation $t_{\alpha}$ to refer to thresholds $t$ corresponding to $\alpha_{t h}$ percentile.

\section{Results and Discussion}

A preliminary analysis over the long-term period (2015-2016) showed that, for both Sicily and Sardinia, the precipitation range of gauged data is greater than that of GPM (Figure 2a, b, d, e). Moreover, the cumulative mean annual precipitation (MAP) for the entire period (2015-2016), obtained by spatially averaging over the two islands the data for GPM and rain gauges, evolve in time with a very similar pattern (Figure $2 \mathrm{c}, \mathrm{f}$ ).
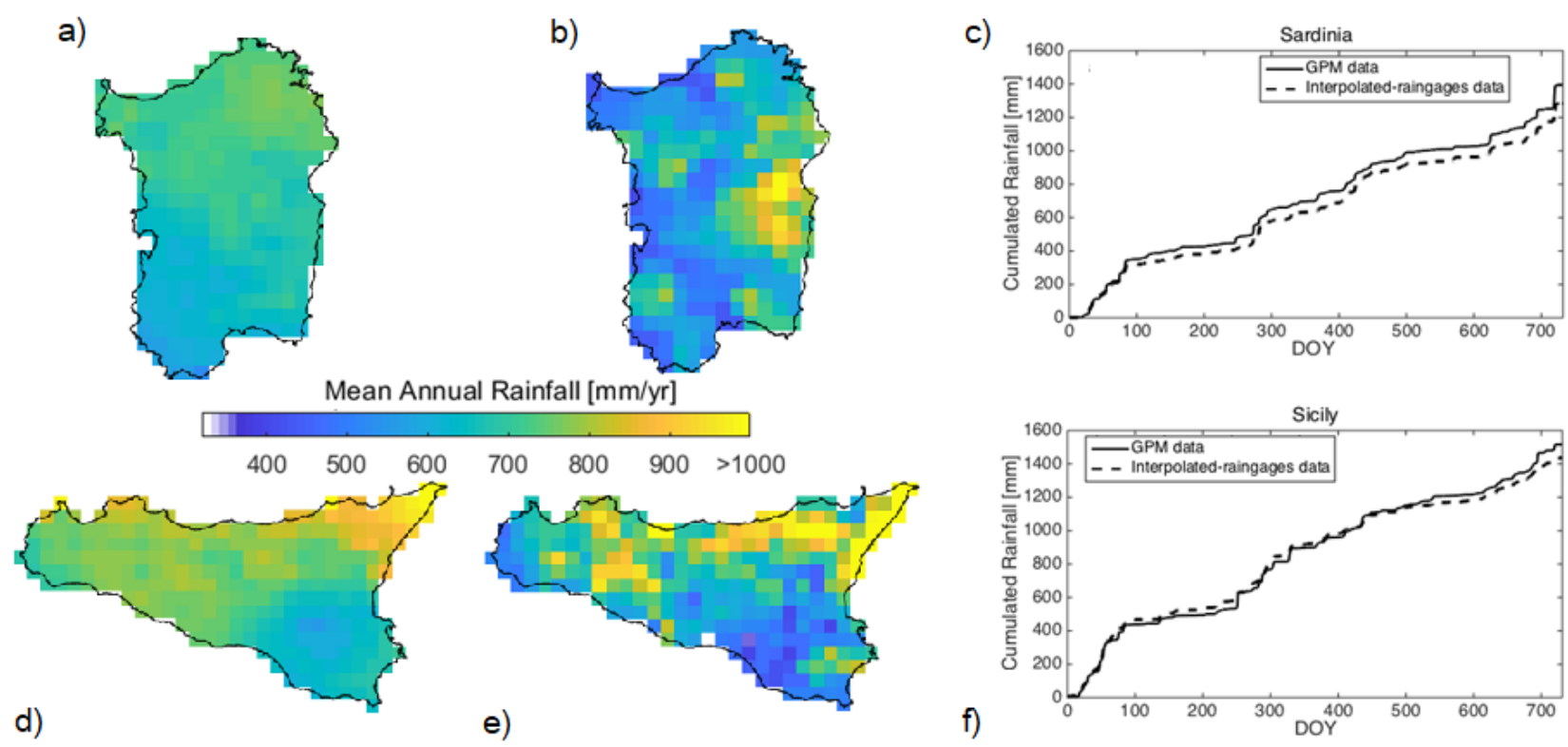

Figure 2 - Maps of the mean annual rainfall (two-year period 2015-2016) estimated with GPM (a, d) and by spatial interpolation of the rain gauges data (b, e). Subplots $c$ ) and f) show a comparison of MAP between GPM (continuous lines) and rain gauges (dashed lines) over the entire Sardinia (c) and Sicily (f) for the twoyear period 2015-2016.

Analysis of categorical and volumetric indexes were conducted only for rainfall values higher than $1 \mathrm{~mm}$. Results showed that the POD and VHI values of the hourly data in Sardinia decrease when the thresholds $t$ increase for $\alpha$ equal to $5 \%, 50 \%$ and $95 \%$. In particular, the VHI values indicate that 
GPM detects more than $95 \%$ of the volume of observed precipitation exceeding the 5 th percentile, and less than $\sim 60 \%$ of the volume of observed precipitation using $t_{95}$. Setting the thresholds $t_{50}$, the VHI values range between 0.6 and 1 showing a good performance of GPM satellite data in detecting the volume of observed precipitation in almost all the Sardinia. The FAR, VFAR, MISS, and VMI values show a general increase as the threshold $t$ rises. In particular, the FAR and VFAR values are high for $t_{95}$, especially in the northeastern and southwestern parts of Sardinia. Similarly, the MISS index shows that GPM does not detect a large fraction of precipitation using $t_{95}$, reaching values very close to 1 , while using $t_{50}$ and $t_{5}$ the MISS values are lower than 0.4 and 0.1 , respectively, showing a good capability of the GPM to detect a large fraction of precipitation. Based on VMI, for $t_{5}$ and $t_{50}$, the fraction of precipitation that GPM does not detect is relatively small (lower than 0.05 and 0.2 , respectively). Considering the CSI index, for $t_{50}$ the overall performance is between 0.4 and 0.6, whereas the VCSI indicates a higher performance score (between 0.5 and 0.9 ). Obviously, the performance score is very high for $t_{5}$ (CSI and VCI higher than 0.85 ).

It is worth noting that the volumetric indexes often provide results better than categorical indexes, which means that in terms of total volume the agreement between GPM and rain gauges is better than in terms of POD and FAR.

Looking at results from indexes computation for hourly data in Sicily, we found similar values as those obtained for Sardinia, although with different spatial patterns.

The same performance metrics were computed also for rainfall fields aggregated at daily scales showing a general improvement as expected and a very similar pattern with comparison with the previous maps. For the sake of simplicity, in Figure 3 we show only the maps at the hourly timescale for both the islands and for $\alpha=50 \%$.

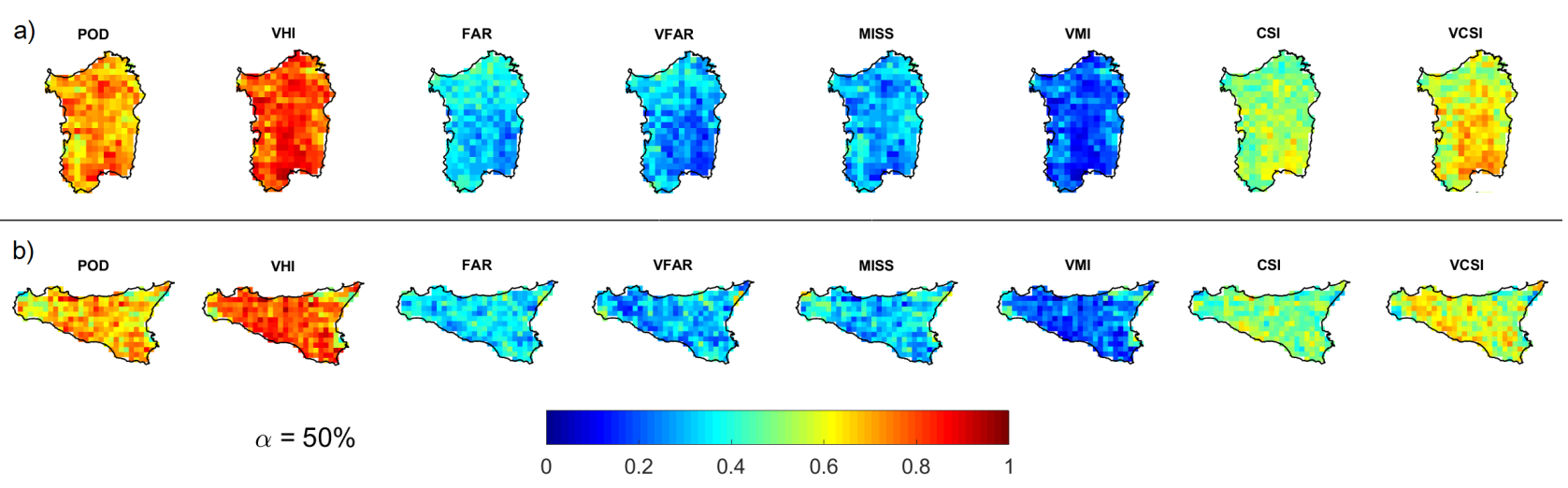

Figure 3 - Comparison of hourly GPM satellite precipitation and interpolated-rain gauges data for a) Sardinia and b) Sicily by categorical and volumetric indexes.

\section{Conclusions}

The results of this study showed that correlation among GPM satellite data and interpolated gauges rainfall is rather good. The volumetric indexes (i.e., VHI, VFAR, VMI, VCSI) often give better results than categorical indexes (i.e., POD, FAR, MISS, CSI), meaning that the agreement between GPM and measures is better in terms of total volume above a given threshold rather than in terms of occurrences above the same threshold. Interestingly, hourly and daily statistics are very similar for the two considered islands, thus demonstrating that GPM satellite data performances are driven by temporal aggregation more than the geographic context. A slightly annual overestimation is observed for the two considered Mediterranean islands, indicating that satellite estimates are not yet fully suitable to represent the corresponding climate. 


\section{Reference}

[1] Hou, A.Y. et al., The global precipitation measurement mission, Bulletin of the American Meteorological Society 95(2014), pp. 701-722.

[2] Lo Conti, F., Hsu, K.-L., Noto, L.V., Sorooshian, S., Evaluation and comparison of satellite precipitation estimates with reference to a local area in the Mediterranean Sea, Atmospheric Research 138(2014), pp. 189-204.

[3] Villarini, G., Krajewski, W.F., Empirically-based modeling of spatial sampling uncertainties associated with rainfall measurements by rain gauges, Advances in Water Resources 31 (2008), pp. 1015-1023.

[4] Huffman, G. et al., GPM Integrated Multi-Satellite Retrievals for GPM (IMERG) Algorithm Theoretical Basis Document (ATBD) Version 4.4. PPS, NASA/GSFC, 30 pp. (2014).

[5] Huffman, G.J., Bolvin, D.T., Braithwaite, D., Hsu, K., Joyce, R., et al., Algorithm Theoretical Basis Document (ATBD) Version 4.6 NASA Global Precipitation Measurement (GPM) Integrated MultisatellitE Retrievals for GPM (IMERG), NASA 1-25. https://pmm.nasa.gov/index.php?q=dataaccess/downloads/gpm (2017a).

[6] NASA, Algorithm Theoretical Basis Document GLOBAL PRECIPITATION MEASUREMENT (GPM) 714 MISSION, http://rain.atmos.colostate.edu/ATBD/ATBD GPM June1 2017.pdf(2017).

[7] Skofronick-Jackson, G. et al., The global precipitation measurement (GPM) mission for science and society, Bulletin of the American Meteorological Society (2016).

[8] Asong, Z., Razavi, S., Wheater, H., Wong, J., Evaluation of Integrated Multisatellite Retrievals for GPM (IMERG) over Southern Canada against Ground Precipitation Observations: A Preliminary Assessment, Journal of Hydrometeorology 18 (2017), pp. 1033-1050.

[9] Behrangi, A., Wen, Y., On the Spatial and Temporal Sampling Errors of Remotely Sensed Precipitation Products, Remote Sensing 9 (2017), p. 1127.

[10] Chen, F., Li, X., Evaluation of IMERG and TRMM 3B43 monthly precipitation products over mainland China, Remote Sensing 8 (2016), p. 472.

[11] Guo, H. et al., Early assessment of integrated multi-satellite retrievals for global precipitation measurement over China, Atmospheric Research 176 (2016), pp. 121-133.

[12] Ning, S. et al., Error Analysis and Evaluation of the Latest GSMap and IMERG Precipitation Products over Eastern China, Advances in Meteorology 2017 (2017).

[13] Prakash, S., Mitra, A.K., Pai, D., AghaKouchak, A., From TRMM to GPM: How well can heavy rainfall be detected from space?, Advances in Water Resources 88 (2016b), pp. 1-7.

[14] Libertino, A., Sharma, A., Lakshmi, V., Claps, P., A global assessment of the timing of extreme rainfall from TRMM and GPM for improving hydrologic design, Environmental Research Letters 11 (2016), p. 054003.

[15] Kim, K., Park, J., Baik, J., Choi, M., Evaluation of topographical and seasonal feature using GPM IMERG and TRMM 3B42 over Far-East Asia, Atmospheric Research 187 (2017), pp. 95-105.

[16] Cannarozzo, M., Noto, L.V., Viola, F., Spatial distribution of rainfall trends in Sicily (1921-2000), Physics and Chemistry of the Earth, Parts A/B/C, 31(18) (2006), Pages 1201-1211, https://doi.org/10.1016/j.pce.2006.03.022.

[17] Di Piazza, A., Conti, F.L., Noto, L., Viola, F., La Loggia, G., Comparative analysis of different techniques for spatial interpolation of rainfall data to create a serially complete monthly time series of precipitation for Sicily, Italy, International Journal of Applied Earth Observation and Geoinformation 13 (2011), pp. 396-408.

[18] Caracciolo, D., Deidda, R., Viola, F., Analytical estimation of annual runoff distribution in ungauged seasonally dry basins based on a first order Taylor expansion of the Fu's equation, Advances in Water Resources (2017b).

[19] Mascaro, G., Deidda, R., Hellies, M., On the nature of rainfall intermittency as revealed by different metrics and sampling approaches, Hydrology and Earth System Sciences 17 (2013), p. 355.

[20] Huffman, G.J., Bolvin, D.T., Nelkin, E.J., Stocher, E.F., V04 IMERG Final Run Release Notes, NASA 1-2. https://pmm.nasa.gov/data-access/downloads/gpm/ V04 IMERG Final Run Release Notes (2017b). 